\title{
THE FINANCIAL CRISIS OF COVID19 AND ITS IMPACT ON NIFTY INDICES OF VARIOUS SECTORS IN INDIA
}

\section{P. RAJESWARI SUSHMA}

Lecturer, Jain College, RR Nagar, Bangalore, India

\begin{abstract}
:
The research paper gives a brief insight of global financial crisis in general and Covid19 in particular. The objective of the paper is analysis of pre pandemic and post pandemic indices of the identified sectors, viz Auto, Pharma, Bank, FMCG, Financial services and IT.

Price indices of key sectors from Nifty (National Stock Exchange) were selected and change percentages of the year 2020 were calculated with respect to price indices of 2019. Huge variations and market volatility in 2020 was depicted through this changed percentages. This study also intended to review the impact of financial crisis on Nifty indices using statistical tools by MVSK parameters (Mean, Variance, Skewness and Kurtosis) for the years 2020 \& 2019. The research further emphasizes in identifying the intensity of impact on various sectors varying from low to high. The price indices of pre and post pandemic were subjected to the statistical concept of hypothesis by determining the t-test. The t-test values had shown positive and negative values, which had shown the intensity of impact owing to Covid19 on different sectors, elaborated under conclusions.

KEYWORDS: Financial crisis, Nifty indices- Covid19 impact, MVSK parameters, Skewness, Kurtosis, Nifty IndicesCovid19 statistical tools, $t$-test.
\end{abstract}

Received: Mar 09, 2021; Accepted: Mar 29, 2021; Published: Apr 08, 2021; Paper Id: IJBMRJUN20214

\section{INTRODUCTION}

The world has seen former Great financial crisis during 1929 and subsequently financial recession in the USA and European countries in 2008. Currently, we are facing a threat and economies are under severe strain due to Covid19 Pandemic.

Covid19 has created lots of disruptions across the globe impacting various sectors and the economy as a whole. This pandemic has pushed the global economy into a recession, which means the economy starts shrinking and growth stops.

According to the IMF, the global economy is expected to shrink by over 3 percent in 2020, the steepest slowdown since the great depression of 1930s and it is estimated that the global economy is expected to grow at $3 \%$ for 2020 which is much worse than the outcome of the crisis that occurred in 2007-08. Economies such as US, Japan, UK, Germany, France, Italy and Spain are expected to contract this year by 5.9, 5.2, 6.5, 7, 7.2, 9.1 and 8 percentages of their GDP's respectively.

As per the latest reports, India is expected to contract by 7-8 \% of its GDP and as per RBI, India has entered into first ever recession in its history. All the major nations have announced economic relief packages ranging from $10-20 \%$ of their GDP's to address interim relief to the damages caused by this ongoing Pandemic. 
Based on preliminary analysis or study, intensity of impact on major sectors owing to Covid19 varies from low impact to high impact and few of the details are reproduced as below:

Sectors with less impact due to Covid19, to name a few are Agriculture/Agricultural products, Telecom Sector, FMCG (Impact would be minimal as majority fall under essential commodities and are need based).

Banking, Electronics, Power, Healthcare/Pharma - these sectors may have medium impact and with ease of lockdown and opening up of economies, may restore to pre covid levels in medium to long terms.

The sectors that have highest impact include Banking (due to moratoriums on loan EMIs, negative market outlook), Aviation, Textiles, Hotels \& Tourism, luxury items- Jewellery etc., retailing including malls \& multiplexes.

\section{OBJECTIVE}

- The study is intended to review the impact of financial crisis on Nifty indices using statistical tools.

- Analysis of pre pandemic and post pandemic indices of the identified sectors.

- Identifying intensity of impact on various sectors varying from low to high impact.

\section{LITERATURE REVIEW}

The past financial crisis includes

Table 1: List of Gathered Financial Crisis

\begin{tabular}{|l|l|l|}
\hline \multicolumn{1}{|c|}{ Year } & \multicolumn{1}{c|}{ Description } & \multicolumn{1}{c|}{ Major Countries Affected } \\
\hline 1930 s & The great recession/ financial crisis & Across the countries \\
\hline 1987 & Financial crisis owing to Stock Market Crash & United states \\
\hline 1990 & High interest rates & Some European countries \\
\hline 1995 & Mexico & $\begin{array}{l}\text { South America (Brazil and Argentina) and } \\
\text { Asia (Philippines, Malaysia, and Thailand) }\end{array}$ \\
\hline 1997 & Asian Financial Crisis & South east Asian countries and Japan \\
\hline 2001 & NASDAQ & USA majorly post 9/11 attacks \\
\hline $2007-2008$ & Global Recession- Mortgages/ Credit & USA, EU and all major economies impacted \\
\hline 2020 & Covid-19 Pandemic- Ongoing & Across all the countries \\
\hline
\end{tabular}

Across the globe, extensive research had been done particularly after the global recession during 2008. The proposed study is intended to concentrate on the impact of sectors in terms of pre and post pandemic Covid19. The impact caused by Covid19 pandemic is yet to be analyzed in detail as the pandemic is far from over and many countries are in fear of a second wave and undergoing extended lockdown.

\section{RESEARCH METHODOLOGY}

Indices prices of NIFTY for some identified sectors listed in Table 2 are being collected from secondary data of NSE website for the period of Jan'20- Nov'20 and for the corresponding period of 2019 are collected. Statistical tools being used for the research include MVSK Parameters - Mean, Variance, Skewness and Kurtosis. 
Table 2: Selected Indices of Sectors

\begin{tabular}{|c|l|c|}
\hline SI No & \multicolumn{1}{|c|}{ Name } & \\
\cline { 1 - 2 } & NIFTY AUTO & \multirow{3}{*}{ Nource } \\
\hline 2 & NIFTYPHARMA & \\
\hline 3 & NIFTY BANK & \\
\hline 4 & NIFTYFMCG & \\
\hline 5 & NIFTY FIN SERVICE & \\
\hline 6 & NIFTY IT & \\
\hline
\end{tabular}

Table 3: Percentage Change in the Prices of Indices during the Sample Period (2019-2020) for NIFTY AUTO

\begin{tabular}{|l|c|c|l|c|}
\hline \multicolumn{5}{|c|}{ NIFTY AUTO } \\
\hline Date & Price & Chg\% & Price & Chg\% \\
\hline Nov & $8,887.95$ & $14.56 \%$ & $8,086.00$ & $-4.30 \%$ \\
\hline Oct & $7,758.40$ & $-1.89 \%$ & $8,449.50$ & $12.76 \%$ \\
\hline Sep & $7,908.10$ & $0.86 \%$ & $7,493.15$ & $6.90 \%$ \\
\hline Aug & $7,840.35$ & $7.70 \%$ & $7,009.30$ & $2.30 \%$ \\
\hline Jul & $7,279.75$ & $8.34 \%$ & $6,851.65$ & $-13.58 \%$ \\
\hline Jun & $6,719.15$ & $8.05 \%$ & $7,928.05$ & $-3.03 \%$ \\
\hline May & $6,218.80$ & $5.38 \%$ & $8,175.50$ & $-2.10 \%$ \\
\hline Apr & $5,901.40$ & $24.73 \%$ & $8,350.60$ & $0.18 \%$ \\
\hline Mar & $4,731.30$ & $-31.47 \%$ & $8,335.35$ & $-0.24 \%$ \\
\hline Feb & $6,903.95$ & $-14.62 \%$ & $8,355.15$ & $1.66 \%$ \\
\hline Jan & $8,086.55$ & $-1.96 \%$ & $8,218.40$ & $-11.01 \%$ \\
\hline
\end{tabular}

Table 4: Percentage Change in the Prices of Indices for NIFTY PHARMA

\begin{tabular}{|l|c|c|c|c|}
\hline \multicolumn{5}{|c|}{ NIFTY PHARMA } \\
\hline Date & Price & Chg\% & Price & Chg\% \\
\hline Nov & $11,880.80$ & $5.67 \%$ & $8,189.95$ & $3.96 \%$ \\
\hline Oct & $11,243.75$ & $-4.49 \%$ & $7,878.15$ & $4.38 \%$ \\
\hline Sep & $11,772.85$ & $6.26 \%$ & $7,547.75$ & $-6.50 \%$ \\
\hline sAug & $11,079.80$ & $-0.62 \%$ & $8,072.05$ & $1.06 \%$ \\
\hline Jul & $11,148.90$ & $11.65 \%$ & $7,987.50$ & $-0.96 \%$ \\
\hline Jun & $9,985.15$ & $2.22 \%$ & $8,065.15$ & $-4.61 \%$ \\
\hline May & $9,768.60$ & $4.08 \%$ & $8,455.10$ & $-10.08 \%$ \\
\hline Apr & $9,385.45$ & $30.78 \%$ & $9,402.50$ & $0.60 \%$ \\
\hline Mar & $7,176.50$ & $-5.28 \%$ & $9,346.55$ & $5.20 \%$ \\
\hline Feb & $7,576.75$ & $-6.90 \%$ & $8,884.85$ & $0.67 \%$ \\
\hline Jan & $8,138.60$ & $1.22 \%$ & $8,825.35$ & $-0.49 \%$ \\
\hline
\end{tabular}

Table 5: Percentage Change in the Prices of Indices for NIFTY BANK

\begin{tabular}{|l|c|c|c|c|}
\hline \multicolumn{5}{|c|}{ NIFTY BANK } \\
\hline & \multicolumn{2}{|c|}{ 2020 } & \multicolumn{2}{c|}{ 2019 } \\
\hline Date & Price & Chg\% & Price & Chg\% \\
\hline Nov & $29,737.25$ & $24.42 \%$ & $31,946.10$ & $6.25 \%$ \\
\hline Oct & $23,900.90$ & $11.42 \%$ & $30,066.25$ & $3.31 \%$ \\
\hline Sep & $21,451.80$ & $-9.69 \%$ & $29,103.15$ & $6.11 \%$ \\
\hline Aug & $23,754.35$ & $9.77 \%$ & $27,427.85$ & $-5.02 \%$ \\
\hline Jul & $21,640.05$ & $1.26 \%$ & $28,876.00$ & $-7.17 \%$ \\
\hline Jun & $21,370.15$ & $10.74 \%$ & $31,105.20$ & $-0.86 \%$ \\
\hline May & $19,297.25$ & $-10.39 \%$ & $31,375.40$ & $5.41 \%$ \\
\hline Apr & $21,534.50$ & $12.49 \%$ & $29,764.80$ & $-2.18 \%$ \\
\hline Mar & $19,144.00$ & $-34.32 \%$ & $30,426.80$ & $13.58 \%$ \\
\hline Feb & $29,147.15$ & $-5.47 \%$ & $26,789.90$ & $-1.85 \%$ \\
\hline
\end{tabular}


\begin{tabular}{|l|l|l|l|l|}
\hline Jan & $30,833.60$ & $-4.13 \%$ & $27,295.45$ & $0.50 \%$ \\
\hline
\end{tabular}

Table 6: Percentage Change in the Prices of Indices for NIFTY FMCG

\begin{tabular}{|l|c|c|c|c|}
\hline \multicolumn{5}{|c|}{ NIFTY FMCG } \\
\hline Date & Price & Chg\% & Price & Chg\% \\
\hline Nov & $31,832.20$ & $8.17 \%$ & $30,975.50$ & $-4.16 \%$ \\
\hline Oct & $29,428.45$ & $-1.38 \%$ & $32,319.75$ & $3.81 \%$ \\
\hline Sep & $29,841.75$ & $-2.46 \%$ & $31,134.50$ & $6.42 \%$ \\
\hline Aug & $30,595.15$ & $-0.90 \%$ & $29,257.35$ & $0.66 \%$ \\
\hline Jul & $30,872.45$ & $2.69 \%$ & $29,065.95$ & $-1.62 \%$ \\
\hline Jun & $30,063.25$ & $2.62 \%$ & $29,546.05$ & $-1.02 \%$ \\
\hline May & $29,296.95$ & $2.19 \%$ & $29,850.40$ & $-1.60 \%$ \\
\hline Apr & $28,669.30$ & $4.94 \%$ & $30,336.90$ & $0.05 \%$ \\
\hline Mar & $27,319.20$ & $-6.79 \%$ & $30,321.40$ & $3.62 \%$ \\
\hline Feb & $29,310.25$ & $-4.76 \%$ & $29,262.85$ & $-1.80 \%$ \\
\hline Jan & $30,775.30$ & $2.17 \%$ & $29,800.55$ & $-2.35 \%$ \\
\hline
\end{tabular}

Table 7: Percentage Change in the Prices of Indices for NIFTY IT

\begin{tabular}{|l|c|c|c|c|}
\hline \multicolumn{4}{|c|}{ NIFTY IT } \\
\hline \multicolumn{1}{|c|}{ Date } & Price & Chg\% & Price & Chg\% \\
\hline Nov & $22,064.30$ & $5.49 \%$ & $14,998.05$ & $-3.61 \%$ \\
\hline Oct & $20,916.85$ & $4.84 \%$ & $15,559.40$ & $0.12 \%$ \\
\hline Sep & $19,951.35$ & $11.28 \%$ & $15,540.15$ & $-2.94 \%$ \\
\hline Aug & $17,928.85$ & $-0.79 \%$ & $16,010.40$ & $2.50 \%$ \\
\hline Jul & $18,071.85$ & $22.49 \%$ & $15,620.20$ & $-1.98 \%$ \\
\hline Jun & $14,754.30$ & $5.31 \%$ & $15,936.45$ & $-1.39 \%$ \\
\hline May & $14,010.50$ & $-0.69 \%$ & $16,160.65$ & $-3.26 \%$ \\
\hline Apr & $14,108.40$ & $10.54 \%$ & $16,705.40$ & $6.89 \%$ \\
\hline Mar & $12,763.65$ & $-16.10 \%$ & $15,628.20$ & $-0.66 \%$ \\
\hline Feb & $15,212.95$ & $-5.77 \%$ & $15,732.00$ & $1.50 \%$ \\
\hline Jan & $16,144.15$ & $3.14 \%$ & $15,499.30$ & $7.33 \%$ \\
\hline
\end{tabular}

Table 8: Percentage Change in the Prices of Indices for Nifty Finservice

\begin{tabular}{|l|c|c|c|c|}
\hline \multicolumn{5}{|c|}{ NIFTY FIN SERVICE } \\
\hline & \multicolumn{2}{|c|}{ 2020 } & \multicolumn{2}{c|}{$\mathbf{2 0 1 9}$} \\
\hline Date & Price & Chg\% & Price & Chg\% \\
\hline Nov & $14,275.25$ & $22.68 \%$ & $14,208.85$ & $5.12 \%$ \\
\hline Oct & $11,636.05$ & $9.54 \%$ & $13,516.45$ & $3.83 \%$ \\
\hline Sep & $10,622.40$ & $-6.73 \%$ & $13,017.30$ & $4.82 \%$ \\
\hline Aug & $11,389.00$ & $6.15 \%$ & $12,418.15$ & $-2.28 \%$ \\
\hline Jul & $10,728.85$ & $1.58 \%$ & $12,707.30$ & $-6.26 \%$ \\
\hline Jun & $10,561.90$ & $10.86 \%$ & $13,556.40$ & $0.57 \%$ \\
\hline May & $9,527.05$ & $-9.87 \%$ & $13,479.80$ & $7.36 \%$ \\
\hline Apr & $10,570.80$ & $13.45 \%$ & $12,555.45$ & $0.09 \%$ \\
\hline Mar & $9,317.30$ & $-31.32 \%$ & $12,544.15$ & $11.73 \%$ \\
\hline Feb & $13,566.45$ & $-5.24 \%$ & $11,227.40$ & $-2.00 \%$ \\
\hline Jan & $14,316.90$ & $-1.65 \%$ & $11,456.40$ & $-1.12 \%$ \\
\hline
\end{tabular}

The percentage changes in prices for the year 2020 have depicted huge variations than that of 2019. A large impact can be seen in the month of March due to COVID outbreak, which led to market volatility. 
Table 9: Calculations Derived from the Values of 2019 for the Identified Sectors

\begin{tabular}{|l|c|c|c|c|c|}
\hline \multicolumn{7}{|c|}{$\mathbf{2 0 1 9}$} \\
\hline & MEAN & VARIANCE & SD & SKEWNESS & KURTOSIS \\
\hline NIFTY AUTO & 7932.06 & $2,87,358.99$ & 536.06 & -1.02 & 2.53 \\
\hline NIFTY PHARMA & 8423.17 & $3,40,609.55$ & 583.62 & 0.40 & 1.93 \\
\hline NIFTY BANK & 29470.63 & $27,60,252.52$ & $1,661.40$ & -0.21 & 1.79 \\
\hline NIFTY FMCG & 30170.11 & $8,86,729.24$ & 941.66 & 0.89 & 2.97 \\
\hline NIFTY IT & 15762.75 & $1,74,805.40$ & 418.10 & 0.54 & 3.48 \\
\hline NIFTY FIN SERVICE & 12789.79 & $7,39,681.64$ & 860.05 & -0.32 & 2.34 \\
\hline
\end{tabular}

Table 10: Calculations Derived from the Values of 2020 for the Identified Sectors

\begin{tabular}{|l|c|c|c|c|c|}
\hline \multicolumn{7}{|c|}{$\mathbf{2 0 2 0}$} & \\
\hline & MEAN & VARIANCE & SD & SKEWNESS & KURTOSIS \\
\hline NIFTY AUTO & 7112.34 & $12,58,428.31$ & $1,121.80$ & -0.54 & 2.68 \\
\hline NIFTY PHARMA & 9923.38 & $25,80,838.05$ & $1,606.50$ & -0.44 & 1.79 \\
\hline NIFTY BANK & 23801 & $1,60,45,083.22$ & $4,005.63$ & 0.66 & 1.94 \\
\hline NIFTY FMCG & 29818.57 & $13,63,138.68$ & $1,167.54$ & -0.39 & 2.93 \\
\hline NIFTY IT & 16902.47 & $87,10,965.50$ & $2,951.43$ & 0.36 & 1.81 \\
\hline NIFTY FIN SERVICE & 11501.09 & $28,82,089.16$ & $1,697.67$ & 0.59 & 1.98 \\
\hline
\end{tabular}

From the means calculated above, it can be inferred that Pharma and IT sectors have an increased trend and other sectors have shown a decline. Standard deviation (SD) \& variance depicts exponentially higher values in 2020 compared to 2019, due to high volatility and substantial variation of values owing to pandemic.

Skewness describes the characteristics of a frequency distribution and measures the symmetry of distribution. A negatively skewed distribution reflects uncertainty and unpredictable approach, as investors may tend to loose and result in discouragement of investment. A positively skewed distribution reflects a predictable approach with desirable returns leading to chances of profits than losses.

Kurtosis depicts heaviness of the distribution tails; a large kurtosis generally refers to a risky investment with small returns and vice versa.It is found that Skewness and Kurtosis do not have a significant change for the sample period of data.

\section{Calculation of t-test for Two Pre and Post Pandemic Periods i.e. 2019 \& 2020 of Different Sectors}

As the price indices of $2019 \& 2020$ are paired observations, we consider t-test with difference between population means using sample means.

Null hypothesis $\mathrm{H}_{0}$ : There is no significant price difference between the periods 2019 \& 2020. (Two tailed test)

Alternative hypothesis $\mathrm{H}_{1}$ : There is significant price difference between the periods $2019 \& 2020$.

$\mathrm{t} \quad=\frac{\bar{d}}{s_{d / \sqrt{n-1}}} \sim t$ with $(n-1) d . f$.

$\mathrm{d}=$ difference between paired observations

$\bar{d}=$ the mean of the difference between paired observations 
$\mathrm{S}_{\mathrm{d}}=\mathrm{S} . \mathrm{D}$ of difference of samples $=\sqrt{\left(\frac{\sum d^{2}}{n}-\left(\frac{\sum d}{n}\right)^{2}\right)}$

Sample size $n=6$; degrees of freedom $=$ n-1 i.e. $6-1=5$

Level of significance $\alpha=5 \%(0.05)$

For 5\% level of significance and with 5 degrees of freedom, the critical value ' $k$ ' that obtained from the 't-test' critical value table is 2.57 i.e. $\mathrm{k}= \pm 2.57$ as it is a two tailed test.

For two tailed test, $\mathrm{H}_{0}$ is accepted, if $-\mathrm{k} \leq \mathrm{t}_{\mathrm{cal}} \leq \mathrm{k}$ (Here, $\left.-2.57 \leq \mathrm{t}_{\mathrm{cal}} \leq 2.57\right)$. Otherwise, $\mathrm{H}_{0}$ is rejected at certain L.O.S $\alpha$ and for different d.f.

Table 11: Table showing t-test Values for Different Sectors

\begin{tabular}{|l|c|l|}
\hline & t value & \multicolumn{1}{|c|}{ Hypothesis Inference } \\
\hline NIFTY AUTO & 1.868 & $\mathrm{H}_{0}$ is accepted \\
\hline NIFTY PHARMA & -2.239 & $\mathrm{H}_{0}$ is accepted \\
\hline NIFTY BANK & 3.636 & $\mathrm{H}_{0}$ is rejected $* *$ \\
\hline NIFTY FMCG & 0.700 & $\mathrm{H}_{0}$ is accepted \\
\hline NIFTY IT & -1.114 & $\mathrm{H}_{0}$ is accepted \\
\hline NIFTY FIN SERVICE & 1.939 & $\mathrm{H}_{0}$ is accepted \\
\hline
\end{tabular}

**From the above table it can be inferred that $\mathrm{t}$ test value for NIFTY BANK indices is $\mathrm{t}_{\mathrm{cal}}=3.636$ which is greater than $\mathrm{k}$ value $(3.636>2.57)$. So, null hypothesis $\mathrm{H}_{0}$ is rejected. Therefore, it can be determined that there is a significant price difference between the periods $2019 \& 2020$. So banking sector is the sector that had a greater negative price impact.

NIFTY AUTO, NIFTY FMCG and NIFTY FINSERVICE are in $-\mathrm{k} \leq \mathrm{t}_{\text {cal }} \leq \mathrm{k}$, so $\mathrm{H}_{0}$ is accepted and there is no significant price difference between the periods $2019 \& 2020$.

Further, in case of NIFTY PHARMA \& NIFTY IT, the $\mathrm{t}$-test value is negative. The negative $\mathrm{t}-$ value indicates a reversal in the directionality of the effect. Though the hypothesis is accepted in these two sectors, they have negative $t$-test value. It can be inferred that there is a positive price increment owing to pandemic.

\section{CONCLUSIONS}

Banking is the worst affected sector due to Covid19 and Pharma and IT are the beneficial sectors.

\section{REFERENCES}

1. Nifty price indices retrieved fromhttps://www.nseindia.com/products-services/indices-sectoral

2. Price indices of different sectors obtained from https://in.investing.com/indices/cnx-fmcg-historical-data

3. Almetwally, Ehab M., and M. I. Gamal. "Discrete Alpha Power Inverse Lomax Distribution with Application of COVID-19 Data." International Journal of Applied Mathematics 9.6 (2020): 11-22.

4. Singh, Brijesh P. "Modeling and Forecasting Novel Corona Cases in India Using Truncated Information: A Mathematical Approach." International Journal of Applied Mathematics \& Statistical Sciences 9.4 (2020): 13-24.

5. Nguyen, Dongthi Thao, and Thu Chung Kieuthi. "New Trends in Technology Application in Education and Capacities of Universities Lecturers during the Covid-19 Pandemic." International Journal of Mechanical and Production Engineering Research and Development (IJMPERD) 10 (2020): 1709-1714. 